Max-Planck-Institut für demografische Forschung

Max Planck Institute for Demographic Research

Konrad-Zuse-Strasse 1 - D-18057 Rostock = Germany = Tel +49 (0) 3812081 - 0 - Fax +49 (0) 3812081 - 202 - www.demogr.mpg.de

MPIDR Working Paper WP 2017-018 I November 2017

\title{
Lifespan dispersion in times of life expectancy fluctuation: the case of Central and Eastern Europe
}

José Manuel Aburto I jmaburto@health.sdu.dk Alyson van Raalte I vanRaalte@demogr.mpg.de

(C) Copyright is held by the authors.

Working papers of the Max Planck Institute for Demographic Research receive only limited review. Views or opinions expressed in working papers are attributable to the authors and do not necessarily reflect those of the Institute. 


\title{
Lifespan dispersion in times of life expectancy fluctuation: the case of Central and Eastern Europe
}

\author{
José Manuel Aburto*1 and Alyson van Raalte ${ }^{\dagger 2}$ \\ ${ }^{1}$ Department of Public Health, Max Planck Center on the Biodemography of Aging, \\ University of Southern Denmark \\ ${ }^{2}$ Max Planck Institute for Demographic Research
}

October 17, 2017

\begin{abstract}
Central and Eastern Europe have experienced considerable instability in mortality since the 1960s. Long periods of stagnating life expectancy were followed by rapid increases in life expectancy and in some cases even more rapid declines before more recent periods of improvement. These trends have been well documented but to date, no study has comprehensively explored trends in lifespan variation. We improve such analyses by incorporating life disparity as a health indicator alongside life expectancy. We analyzed how lifespan variation has changed since the 1960s for 12 countries from the region and determined the ages which have contributed the most to the observed variability in age at death. Furthermore, we quantified the effect of mortality related to alcohol consumption on life disparity since 1994. Our results showed that life disparity was high and strongly fluctuating over the time period. Life expectancy and life disparity moved independently from one another, particularly during periods of life expectancy stagnation. Fluctuations in mortality were, to a large extent, directly or partially attributable to changes in alcohol consumption. These trends run counter to the common patterns observed in most developed countries and contribute to the life expectancy-disparity discussion by showing that expansion/compression levels do not necessarily mean lower/higher life expectancy or mortality deterioration/improvements.
\end{abstract}

\footnotetext{
*jmaburto@health.sdu.dk

†vanRaalte@demogr.mpg.de
} 


\section{Introduction}

The 20th century was marked by sizable improvements in mortality and health in most countries in the world (World Health Organization 2000). However, these improvements were unevenly shared in the second half of the past century, as parts of Central and Eastern Europe experienced an unprecedented period of stagnation and, in some countries, decrease in life expectancy at birth after 1960 (Human Mortality Database 2016). The long term combination of a failure to complete the epidemiologic transition by reducing cardiovascular diseases (Caselli et al. 2002), along with fluctuation in alcohol and violence (Bye 2008, Leon et al. 1997), led to lower levels of life expectancy and larger mortality inequalities in this region compared with western countries in Europe (Mackenbach et al. 2008). The high mortality among young men is at the heart of Eastern European trends in life expectancy (McKee and Shkolnikov 2001). For example, male life expectancy stagnated at a level between 65 and 70 years from the 1960s to the mid-1980s in Belarus, Bulgaria, Czech Republic, Estonia, Hungary, Latvia, Lithuania, Poland, Slovakia, Slovenia and Ukraine. During this same period, Russia experienced the lowest male life expectancy in the region, followed by a brief period of sizable improvements in life expectancy due to Gorbachev's anti-alcohol campaign (Leon and Shkolnikov 1998). After 1987 the mortality experiences in the region diverged. Life expectancy increased continuously in Slovenia and the Czech Republic. The rest of the countries, particularly those from the former Soviet Union, experienced a pronounced period of deterioration up to the mid-1990s. Mortality increases among Russian and Latvian men were especially sharp, with life expectancy losses of around 7.5 years between 1987 and 1994, which led to levels not seen since the 1950s (Shkolnikov et al. 2001). Since the mid-1990s, life expectancy has mostly been increasing throughout the region, but at different rates. As a result, large regional differences in survival have emerged. For instance, the 2010 gap in male life expectancy between Slovenia and Russia was more than 13 years (Human Mortality Database 2016).

National trends in life expectancy are important and have been extensively studied in the region (Meslé 2004, Meslé et al. 2000, Rychtarikova 2004, Shkolnikov et al. 2001; 2006, Leon 2011). Nonetheless, as an average, life expectancy conceals considerable heterogeneity in individual mortality trajectories (Edwards and Tuljapurkar 2005, Wilmoth and Horiuchi 1999). This age-at-death variation, hereafter referred to as life disparity or lifespan variation, is an important dimension of inequality as it summarizes the uncertainty in the timing of death. Until now, trends in lifespan variation have mostly been studied in the context of mortality decline at all ages (Edwards and Tuljapurkar 2005, Smits and Monden 2009, Vaupel et al. 2011). Alongside increases in life expectancy, ages at death have become more predictable (i.e. lifespan variation has decreased). This is because mortality decline over young ages has outpaced mortality decline at older ages, compressing most deaths into a narrower age window (Vaupel et al. 2011).

This need not be the case. At the subpopulation level, numerous instances have been documented of lifespan variation increase occurring alongside increases in life expectancy (van Raalte et al. 2014, Sasson 2016, 
Seaman et al. 2016, Brønnum-Hansen 2017), mainly due to stalls in working age mortality decline occurring alongside continued old age mortality decline. To date, no comprehensive studies of lifespan variation have been undertaken under periods of life expectancy decline.

We complement the existing literature by focusing on the Central and Eastern European case, which shows atypical periods of mortality upheaval and substantial life expectancy fluctuation. This region is particularly interesting because its age pattern of mortality change was very different from that observed in western countries (Meslé 2004). Since the sharpest fluctuation in age-specific mortality occurred over working ages (Rehm et al. 2007), it is a priori unclear what the net effect would be on variability. We analyzed how lifespan variation has changed since the 1960s for 12 countries from this region and determined the ages and causes of death that contributed the most to the observed change in lifespan variation, with a particular focus on the impact of alcohol-attributable mortality.

Our analyses revealed three important findings: (1) the acute mortality crises of the 1990s caused greater year-to-year fluctuation in lifespan variation than in life expectancy, (2) life expectancy and lifespan variation moved independently, particularly during periods of stagnation and uneven age-specific mortality change, and (3) mortality amenable to alcohol consumption occurred over ages that both increased and decreased lifespan variation, with different net effects depending on the country and time period. These results underscore the added value of looking at other summary measures of mortality beyond the mean.

\section{Data \& Methods}

\section{Dispersion measure \& demographic methods}

For each population, we investigated life expectancy and lifespan variation since birth. We decided not to analyze variability at death conditioned on survival to a childhood age, as previous studies have done (e.g. Edwards and Tuljapurkar (2005), Smits and Monden (2009)), because of the arbitrariness of choosing a starting age and because infancy and childhood are major contributors to lifespan inequalities that we did not want to overlook. Several dispersion measures have been proposed to analyze lifespan variability (van Raalte and Caswell 2013, Wilmoth and Horiuchi 1999). In this article, we use life disparity $\left(e^{\dagger}\right)$ as a dispersion indicator (Vaupel and Canudas-Romo 2003). It is defined as the average remaining life expectancy when death occurs; or life years lost due to death. For example, when death is highly variable, some people will die well before their expected age at death, contributing many lost years to life disparity. When survival is highly concentrated around older ages, the difference between the age at death and the expected remaining years decreases, and life disparity gets smaller. It can be expressed as

$$
e_{x}^{\dagger}=\frac{1}{\ell_{x}} \int_{x}^{\omega} \ell(a) \mu(a) e(a) d a
$$


where $\ell(a), \mu(a), \omega$ and $e(a)$ are the survival function, the force of mortality, the open-aged interval (110+ in our case), and remaining life expectancy, respectively. We selected this measure because of its easy public health interpretation, which equals the average life expectancy losses attributable to death (Shkolnikov et al. 2011), and its decomposable and additive properties (Zhang and Vaupel 2009). The $e^{\dagger}$ measure has the additive property that, once it has been decomposed by age between two periods, the sum of every age-specific contribution to the difference is the total change in $e^{\dagger}$ between these two periods. These properties allow us to quantify the impact of mortality at different ages, and from different causes, and to separate ages that decrease lifespan variability from those that increase it by using demographic methods (Zhang and Vaupel 2009, Shkolnikov et al. 2011). We perform such decomposition by single age, period and cause of death based on a continuous change model (Horiuchi et al. 2008) that has the advantage of assuming that covariates change gradually along the time dimension, for the age-cause decomposition we used the 5-year age group mortality rates from the Human Cause-of-Death Database (2016). All the calculations were performed using $R$ (R Core Team 2000) and are fully reproducible with the available code and additional information ${ }^{1}$.

The close relationship with other lifespan variation indices, such as Keyfitz's life table entropy (Vaupel and Canudas-Romo 2003), and the high correlation between them suggests that conclusions would likely be the same regardless of the measure chosen (van Raalte and Caswell 2013, Vaupel et al. 2011, Wilmoth and Horiuchi 1999).

\section{Data}

We used all-cause death counts, population exposures and period life tables from the Human Mortality Database (2016) for 12 countries from 1960 to the most recent year available in the data set. The countries included in the study were Belarus, Bulgaria, Czech Republic, Hungary, Poland, Russia, Slovakia, Ukraine, Slovenia, Estonia, Latvia and Lithuania. Data for Slovenia was only available from 1983. The data are by single age, year, sex and country.

Cause of death data came from the newly developed Human Cause-of-Death Database (2016), which provides coherent cause-specific mortality data time series for eight of the countries in the study (Belarus, Czech Republic, Poland, Russia, Ukraine, Slovenia, Estonia, Latvia and Lithuania). For inclusion into the database, a universal and standardized methodology was undertaken to redistribute deaths between 104 disease categories in 5-year age groups. We used these data to get the cause-specific proportion by 5 -year age groups. This has effectively eliminated ruptures surrounding revisions of the International Classifications of Disease (ICD), and substantially reduced cross-country comparability problems owing to different coding practices, particularly from the use of ill-defined and unknown causes. We truncated the cause-of-death analysis at

\footnotetext{
${ }^{1}$ Link to code removed to avoid identifying information
} 
age 85 because of classification quality and presence of comorbidities and focus on the period after 1994 because comparable information is available for the eight countries (Human Cause-of-Death Database 2016). Furthermore, we focus on this period because it coincides with the beginning of the divergence in Eastern European mortality trends, particularly between the former Soviet and Central European countries (Meslé 2004).

Cause of death classification

Injurious alcohol consumption has long been identified as a major determinant of premature mortality in Eastern European countries (Leon et al. 1997, McKee and Shkolnikov 2001, Rehm et al. 2007, Grigoriev and Andreev 2015). We aimed to identify the effect of mortality related to alcohol consumption on lifespan variation from 1994 to 2010 .

We grouped causes of death into four categories according to the degree to which they associate with alcohol consumption and abuse (for details on the ICD-10 codes for each cause, see Table 1). The categories are as follows: 1) Alcohol-attributable conditions (for example, mental and behavioral disorders due to use of alcohol, alcohol liver disease, accidental poisoning by alcohol); 2) Conditions amenable to alcohol consumption (such as ischemic heart disease (IHD), stroke and transportation accidents); 3) Other conditions susceptible to alcohol consumption (other external causes and other circulatory conditions); and 4) all other causes (labeled as residual causes). The first category (alcohol-attributable conditions) refers to those health conditions that by the ICD definition identifies alcohol consumption as a necessary cause and that previous research has identified as wholly attributable to alcohol consumption (Rehm et al. 2010). We additionally include liver cirrhosis in this first category because around three-quarters of deaths from this cause in the region are thought to be attributable to alcohol (Rehm et al. 2003), and it is common practice to include it as a condition attributable to alcohol consumption (Rehm et al. 2003; 2010).

The second category, conditions amenable to alcohol consumption, pertains to conditions that are not wholly attributable to alcohol consumption, but that have been linked with alcohol consumption patterns. For example, heavy drinking is associated with physiological mechanisms that increase the risk of IHD and stroke death (Rehm et al. 2010). Similarly, alcohol consumption has been shown to have a causal impact on different injuries (Rehm et al. 2003). We focus on transport injuries because Latvia, Lithuania and Russian report the highest in Europe (Avenoso and Beckmann 2005) and recent developments in infrastructure and safety may have had an important impact in reducing transportation injuries in some countries (World Health Organization 2009; 2013). From this group of causes we are more interested in examining changing trends, which we expect to be more closely related to changing alcohol consumption patterns than the baseline levels, which have numerous determinants. 
The third category, other conditions susceptible to alcohol consumption, includes the rest of external causes, such as self-inflicted injuries, and the rest of circulatory diseases. We analyze them separately to complement the broad categories of external and circulatory disease included in the second category. Although additional rare causes of death can be linked to alcohol consumption, we do not include them in our study because their absolute contributions to mortality change are likely to be very small in the set of countries that we study (Grigoriev and Andreev 2015).

[Table 1 about here]

In what follows, we present our results on Eastern European males only. Mortality fluctuated more strongly among men, which more clearly illustrates the added value of looking to lifespan variation in times of crisis. In most cases, trends were similar for both sexes, but the magnitude of change was less for females. Full results are presented in the supplemental material for females.

\section{Results}

Age-specific mortality rates of improvements

For a descriptive look at age-specific mortality change over the period, we first examined the average annual rate of mortality improvement (Rau et al. 2013) with smoothed mortality surfaces (Camarda 2012) for males in 12 Central and Eastern European countries 1. The respective values are expressed in percent. Little change or no improvement $(-0.5 \%$ to $0.5 \%)$ is depicted in white. Improvement in mortality (i.e. mortality decline) is shown in blue and mortality increase in red. Darker tones mean major changes in mortality rates.

Almost every country experienced a near-continuous 20-year period of increasing mortality rates, from the mid-1960s to the mid-1980s. Mortality rate increases were mainly concentrated in the ages between 20 and 80 years. After 1985, 7 countries experienced sizable reductions in mortality rates (Belarus, Estonia, Latvia, Lithuania, Poland, Russia and Ukraine) for a period of around 5 years. Opposing this trend, in the early 1990s most countries that were part of the former Soviet Union such as Estonia, Latvia, Lithuania, Russia and Ukraine experienced intense mortality increases. Finally, since the mid to late 1990s Slovakia, Slovenia, Hungary, Latvia, Poland, Estonia and Czech Republic have reduced age-specific mortality rates at almost every age. The biggest improvements were related to the most recent years.

[Figure 1 about here]

Trends in life expectancy and lifespan disparity 
Figure 2 shows male $e_{0}$ and $e^{\dagger}$ trends for Central and Eastern European countries from 1960 to the most recent year available. From 1960 to $1984 e_{0}$ stagnated for most of the countries, some of them even experienced a slow and steady decline (e.g. Russia, Latvia, Estonia, and Ukraine). This period was followed by a notable increase in $e_{0}$ in the mid-1980s, closely corresponding to, although sometimes preceding, Gorbachev's anti-alcohol campaign shaded in red. However, after 1987 life expectancy among these countries started to diverge: Central European countries experienced a short period of stagnation or decline followed by an upward trend until the end of the study. Russia, Latvia, Estonia, Ukraine, Belarus and Lithuania experienced a marked decrease in $e_{0}$ from 1988 to 1994. From that point on, $e_{0}$ improved everywhere, with the exception of Russia, Belarus and Ukraine. These last countries exhibited a final decrease (Russia) or stagnation (Belarus, Ukraine) in life expectancy between 1998 and the mid-2000s, followed by sharp increases in the final period from the mid-2000s to the latest available year. Importantly, Estonia shows exceptional improvements since the mid 1990's, particularly in women.

Life disparity showed similar patterns of stagnation between 1960 and 1980 as was seen for $e_{0}$. Russia and Lithuania exhibited the highest levels in this period, between 17 and 19 years lost due to death; while the Czech Republic presented the lowest level throughout the same years, between 13 and 14 years. Importantly, the Czech Republic was not the regional record $e_{0}$ holder during these years. Around the mid-1980s all countries experienced compression of mortality, i.e. decreases in $e^{\dagger}$, with the exception of Hungary. After 1991, Lithuania, Russia, Latvia and Estonia experienced significant increases in $e^{\dagger}$ with the peak in 19941995. During this peak, the observed $e_{0}$ levels differed from historic levels observed when $e^{\dagger}$ was equally high. Central European countries experienced continuous reductions in $e^{\dagger}$ after 1994, whereas it was less systematic in Latvia and Lithuania. The rest of the countries also experienced declines after that year up to 2010-2014, but with greater fluctuation. Such declines, however, were not as steep as the $e_{0}$ increases in these countries.

[Figure 2 about here]

Absolute and relative changes in life expectancy and lifespan disparity

Contrasting the changing levels of $e_{0}$ and $e^{\dagger}$ from Figure 2 suggests that in periods of stagnation and mortality upheavals similar levels of $e_{0}$ do not correspond to similar levels in $e^{\dagger}$. Therefore, we analyzed the direction and magnitude of change in the two measures.

Figure 3 shows absolute and relative yearly changes (first differences) in $e_{0}$ and $e^{\dagger}$ by sex and period. If a negative relationship exists between $e_{0}$ and $e^{\dagger}$, changes would concentrate in the top left and bottom right quadrants. If points fall in the top right and bottom left quadrants, the relationship is positive. We focus on the latter changes and quantify their frequency in three different time periods relating to overall 
mortality trends. The period 1960-1987 contains a mixture of stagnation, steady decline and improvements in life expectancy; 1988 to 1995 was a period of decreasing life expectancy; and 1996 onwards is characterized by divergence between countries in life expectancy trends, with recent life expectancy improvements. Grey dots correspond to a negative association between life expectancy and life disparity (e.g. increases in $e_{0}$ with decreases in $e^{\dagger}$ ), while red dots correspond to a positive association (e.g. increases in $e_{0}$ with increases in $e^{\dagger}$ ). Since Russia is both the largest country included in the analysis and the country with the most volatile mortality trends, we marked its points in dark blue. Absolute changes (top panel) are easy to interpret since they reflect the changes in life expectancy and life disparity measured in years. However, since the maximum value of $e_{0}$ is much higher than the maximum value of $e^{\dagger}$, it is not surprising that changes vary more strongly on the $e_{0}$ axis than the $e^{\dagger}$ axis. Therefore, it is also important to analyze changes in both measures in relative terms (bottom panel). This allows us to quantify the intensity of such changes.

During 1960-1987, almost one-third of the yearly changes in mortality resulted in $e_{0}$ decreases and decreases in $e^{\dagger}$, in both males $(33.2 \%, 95 \%$ CI $[27.9,38.5])$ and females $(32.6[27.3,37.9])$. These were mostly small changes corresponding to less than one year of life. Conversely, 20.9\% [16.3,25.5] (males) and 25.9\% $[21,30.9]$ (females) of $e_{0}$ increases corresponded to $e^{\dagger}$ increase. This means that, by adding both quadrants, the measures in this period were moving in the same direction more than half of the time. In 1988-1995, when most of the changes corresponded to substantial decreases in $e_{0}$, the two indices moved in the same direction about a quarter of the time. Finally in the period 1996 onwards, characterized by mortality convergence, more than a third of all points related to movements in the same direction for both measures.

Moreover, even when the two measures moved in the direction expected from a negative correlation, the magnitude of change in life expectancy did not reflect the same magnitude of change in life disparity. For example, Russia lost 3 years of male life expectancy (around 5\%) between 1992 and 1993, while life disparity showed a much smaller increase (less than 2.5\%). Most of the time, however, $e^{\dagger}$ experienced larger relative changes than $e_{0}$, evidenced by more movement along the horizontal than the vertical axis in the bottom panel of Figure 3.

[Figure 3 about here]

\section{Age-specific decomposition}

Figure 4 shows age-specific contributions to the change in $e^{\dagger}$ for ages 5 and above ${ }^{2}$, respectively, by period (results for ages 0-4 depicted in Supplemental material Figure $7^{3}$ ). Bars on the left (decreases in variation)

\footnotetext{
${ }^{2}$ For age-specific contributions to life expectancy, see the supplemental material.

${ }^{3}$ Declines in mortality below age 5 were the strongest age-category contributor to changes in life disparity over the period under study, with most of the decline occurring over the 1960-1980 period. For this reason they are plotted separately from other ages with a different scale used on the $x$-axis in the supplemental material. The decline was near monotonic in most countries, with only minor differences between countries, especially when compared to the much larger between-country differences at other ages.
} 
come about from mortality decrease at young ages or increase at old ages, separated by a threshold age. Conversely, bars on the right (increase in variation) are produced by mortality increase at young ages or mortality decrease at old ages. The periods are grouped by the changes in life expectancy trends ${ }^{4}$ depicted in Figure 2: stagnation $^{5}$ from 1960 to 1980 (blue), improvements from 1980 to 1987 (green), deterioration from 1987-1994 (red), divergence from 1994-2000 (purple), and convergence over the period 2000-2010 (orange). If the colors are all lined up on one side it suggests that mortality changed in different directions for the different ages.

Over the long period of $e_{0}$ stagnation (blue), changes in $e^{\dagger}$ were driven by increases in mortality at all depicted ages, which expanded age at death variability in young and young-adult ages; and compressed variation at older ages in all countries ${ }^{6}$. It is worth noting that these changes offset each other since the old age compression was comparable to the net expansion of mortality experienced by children and younger adults in Russia, Slovakia, Ukraine, and Poland. In fact, in Bulgaria and Belarus, the compression caused by mortality increase over older ages was greater than the expansion made by mortality increase among younger ages. A similar pattern was observed during the period of $e_{0}$ deterioration (red). Lifespan variability mostly increased, which was explained by expansion of mortality at young and middle ages, alongside smaller compression at older ages during this period. However, some Central European countries showed improvements in mortality between ages 5 and 30 that resulted in overall $e^{\dagger}$ declines.

Opposing these trends, in the period of improvements (green), Russia and other countries of the former Soviet Union followed a western pattern with $e^{\dagger}$ decreases mostly caused by mortality decline at younger ages outpacing mortality decline over older ages and leading to overall compression in mortality. Mortality change was smaller and the age patterns of change were more variable in Central European countries during this period. From 1994 onward (purple and orange), all countries experienced $e^{\dagger}$ compression at younger ages and expansion at older ages overall. However in the early years (1994-2000), mortality increases at younger ages led to increases in $e^{\dagger}$ in Russia, Ukraine and Belarus before reversing itself in recent years. Importantly, during this post-1994 period, mortality fluctuations at relatively young ages (20-50) had the largest impact on $e^{\dagger}$ changes.

[Figure 4 about here]

Alcohol-related mortality and its contribution to changes in lifespan variability

\footnotetext{
${ }^{4}$ Periods were determined using a divisive hierarchical estimation algorithm for multiple change points analysis using the package ecp in $R$. The break points in slope changes in the coefficient of variation of male life expectancy were 1960, 1976, 1986, 1993 and 2001. We decided to use these break point +- 3 years to coincide with historical trends and facts such as Gorbachev's anti-alcohol campaign and the dissolution of the Soviet Union.

${ }^{5}$ We labelled the period as "stagnation", even though some countries experienced a steady decline, because the coefficient of variation of life expectancies during this period was stagnant.

${ }^{6}$ Data unavailable for Slovenia before 1983.
} 
Table 2 shows the net contribution of alcohol-related mortality to changes in life disparity for the most recent periods of divergence (1994-2000) and convergence (2000-2010). From 1994 to 2010 all the countries included in our study decreased $e^{\dagger}$. Ukraine experienced a small increase (0.06 years) between 1994 and 2000 that was offset in the following period (-0.84 periods). Most of the declines observed were due to a decrease in mortality from external causes and birth conditions. Mortality attributable to alcohol produced mixed results: while in some countries such as Estonia, Latvia, and Russia, these causes of death contributed to decreasing lifespan disparity over the full period 1994-2010, other countries experienced increases in 19942000 followed by decreases or vice versa (Czech Republic, Lithuania, Poland and Ukraine). Belarus was the only country that showed increases in life disparity caused by alcohol-attributable mortality. Similar results were found for IHD. However, cancers contributed positively to life disparity, increasing lifespan variation, in all countries with the exception of Belarus.

[Table 2 about here]

Figures 5 and 6 show how alcohol-related mortality contributed to the changing $e^{\dagger}$ at different ages for a subset of Central and Eastern European countries ${ }^{7}$. The sum of the age-specific contributions by causes of death result in the values in Table 2. Red colors are related to causes attributable to alcohol consumption. The orange refers to Ischemic Heart Diseases (IHD), green to stroke mortality and purple to transportation accidents. Blue and dark grey colors relate to other external causes and the rest of circulatory diseases, respectively. Infectious \& respiratory, cancers and birth conditions are depicted in pastel green, magenta and pink. The remaining causes and mortality at ages 85 and above are depicted in grey.

Results show that in Russia, Ukraine and Belarus $e^{\dagger}$ stagnated between 1994 and 2000 because age-specific mortality change was small and uneven across ages. On the contrary, the Baltic countries (Latvia, Lithuania and Estonia) experienced sizable reductions in mortality at all ages, and particularly strong compression of early adult mortality. These mortality reductions were primarily in causes amenable to alcohol, namely external mortality and transport accidents at younger ages, and IHD and stroke mortality at older ages. Causes directly attributable to alcohol consumption were also a strong contributor to mortality reduction between the ages of 20 and 60 in Lithuania. Poland and Czech Republic fell somewhere in-between the two other groups of countries, with small reductions in IHD and circulatory disease, but experiencing little change in external mortality.

From 2000-2010 all countries experienced improvements in survival and decreases in $e^{\dagger}$, particularly from causes amenable or susceptible to alcohol consumption. Most of the mortality compression below the threshold age occurred in early adulthood, particularly from external mortality. Conditions wholly attributable to alcohol consumption played a negligible role in $e^{\dagger}$ compression or expansion over the period, with the exception of Lithuania, where it increased between ages 30 and 45 . Above the threshold age,

\footnotetext{
${ }^{7}$ For age-cause-specific contributions to life expectancy in the same periods, see the supplemental material.
} 
mortality was variable by cause. Reduction in mortality from conditions amenable to alcohol consumption (IHD, stroke, and external causes) was considerable in Russia, Latvia and Estonia, but nearly absent in Ukraine, Lithuania and Belarus. Estonia experienced increases in other circulatory disease (i.e. non-IHD or stroke), Belarus experienced increases in transport accidents, and the other Baltic countries experienced increases in mortality unrelated to alcohol at older ages during this period.

[Figures $5 \& 6$ about here]

\section{Limitations}

The limitations of our study should be mentioned. First, different measures of inequality differ from one other in formal properties and in the degree of their sensitivity to age-specific mortality change (van Raalte and Caswell 2013). Other authors have chosen measures of relative inequality, such as the Gini coefficient, Keyfitz's entropy or the Theil index of inequality (Shkolnikov et al. 2003, Moser et al. 2005, Smits and Monden 2009, Colchero et al. 2016). As a robustness check, we performed a sensitivity analysis replicating all the results shown in this study with the Gini coefficient following Shkolnikov et al. (2003) (see supplemental material). We did not find major differences with the results discussed in this article.

Secondly, estimating alcohol-attributable mortality is not straightforward. For one, unlike smoking, heavy alcohol consumption can have both immediate and cumulative impacts on mortality. In any period certain causes, for instance traffic accidents or alcohol poisoning, may change immediately in response to changing consumption patterns, while others, for instance liver cirrhosis, mainly reflect past consumption behaviour (Menon et al. 2001, Rehm et al. 2003), and still others are such as IHD have been implicated in both immediate binge drinking mortality (Kauhanen et al. 1997) and elevated mortality risks from long-term heavy drinking (Roerecke and Rehm 2014). Thus using a cause of death based attribution method is only sensible in countries with relatively stable temporal patterns of alcohol consumption (Kraus et al. 2015, Martikainen et al. 2014), which is certainly not the case in our study. An alternative is to derive alcohol-attributable mortality from follow-up longitudinal studies that report consumption patterns. Even if such surveys were available for some countries included in the study, self-reported alcohol consumption data are often biased and underestimate actual consumption because individuals forget drinking occasions, underrate drink size and are not able to remember the quantity of drinks in every drinking session (Livingston and Callinan 2015, Bellis et al. 2009). A third commonly used approach is to link mortality with changes in alcohol sales (Evgeny 2010). A limitation to this approach is that the total alcohol consumption might not matter so much as the alcohol consumption behaviour. Indeed low levels of alcohol consumed at a regular basis may even be protective against mortality (Bell et al. 2017, Rehm et al. 2010, Klatsky et al. 1974, Roerecke and Rehm 2014). Moreover, alcohol sales do not include homemade alcohol, which is substantial in the region (Popova et al. 2007, McKee et al. 2005), and can be distorted by alcohol tourism (Mäkelä and Österberg 2009, Rabinovich et al. 2009). 
For these reasons, we took a more cautious approach that aims to at least partially attribute the changes in mortality trends to alcohol consumption without over or under-interpreting its absolute impact on mortality at any given time. Although the causal effect of alcohol is not clear in some conditions, such as accidents, violent deaths and IHD, we included them as "amenable to alcohol consumption". Smoking-attributable mortality is also high in the region (Ezzati and Lopez 2003) and could be a determinant of rising IHD and stroke mortality in some periods, yet we would not expect it to cause major departures in the slope or direction of change in mortality trends. On the other hand, departures from baseline alcohol consumption levels would increase or decrease mortality from these alcohol-amenable causes in comparison to the baseline period. In other words, when IHD, violent deaths and accidents all increase from one period to the next, it is strongly suggestive of increasing alcohol-related mortality and vice-versa.

Finally, coding practices at old ages and the different definitions of infant deaths of the Soviet Union are an issue in the mortality data. We mitigated this by truncating our cause-of-death analysis at age 85 and using comparable data from the Human Cause-of-Death Database (2016).

\section{Discussion}

The results derived from this study allowed us to analyze and compare long time series in life disparity for 12 countries from Central and Eastern Europe. They shed light into the determinants of variation in age at death across time and countries. In addition, we used high quality comparably reconstructed cause of death data to analyze the role of alcohol-related mortality on changing lifespan variation based on a reflective classification. This is the first comparative study of the region making use of the Human Cause-of-Death Database (2016) in this region. Over the study period, life expectancy and life disparity moved independently from one another, particularly during periods of life expectancy stagnation. Fluctuations in life disparity were, to a large extent, caused by fluctuation in midlife mortality that was directly or partially attributable to changes in alcohol consumption.

Changes in life expectancy $\left(e_{0}\right)$ and life disparity $\left(e^{\dagger}\right)$

Previous studies have found a close negative correlation between life expectancy and life disparity when measured over all ages (Wilmoth and Horiuchi 1999, Vaupel et al. 2011, Colchero et al. 2016). These studies were carried out over long periods of a hundred years or more, and mostly included Western countries with near-monotonic life expectancy increases. Importantly, two major phenomena were observed from the mid-nineteenth Century to the present: first was a drastic reduction of infectious disease mortality followed 
later by a major decline in cardiovascular disease mortality. These epidemiological changes can equally be considered as a redistribution of deaths from young to middle ages and later from middle to older adult ages (Robine 2001). In both cases, contemporaneous mortality decline over "younger" ages (defined as ages that compress mortality into a smaller age interval) outpaced decline over "older" ages (ages where mortality decline leads to deaths occurring over a larger age interval), which caused life disparity to decrease in lockstep with life expectancy increase.

Central and Eastern European countries run counter to this narrative. Although they too experienced the sharp declines in infectious disease mortality up to the mid-twentieth Century, mortality at midlife stalled or even increased for most of the last half of the twentieth Century (McKee and Shkolnikov 2001), with no appreciable declines in cardiovascular mortality until very recently (Caselli et al. 2002, Grigoriev et al. 2014, Meslé 2004). As our results made clear, mortality change at different ages was far from even, with the result that changes in lifespan variation did not correspond in intensity or even direction with changes observed in life expectancy.

Moreover, by looking at long term trends in life expectancy and lifespan variation in the region, it was apparent that between-country differences in lifespan variation have and continue to be larger (in relative terms) than between-country differences in life expectancy (coefficients of variation for $e_{0}$ and $e^{\dagger}$ in 2014 are 0.06 and 0.11 , respectively). However, while mortality change after the break-up of the Soviet Union led to sharply diverging trends in life expectancy, divergence in lifespan variation between countries was less dramatic. This complements recent work by Timonin et al. (2016) who found that differences between geopolitical regions in life expectancy were more important than increasing within-region disparities in ages at death in driving life expectancy divergence in developed countries from 1970 to 2010.

Increasing lifespan variability underscores the rise in within-group heterogeneity and the uncertainty that people face regarding their age at death. From a public health perspective, these results are important because they disclose inequalities underlying population health that could not be identified by looking at life expectancy alone. Similar outcomes have been found previously for some countries and they are seen as outliers that are not following the classic western trend (Wilmoth and Horiuchi 1999, Zhang and Vaupel 2009). For instance, stagnating or increasing lifespan variation has been seen alongside life expectancy increase among lower socioeconomic groups or regions in Europe (van Raalte et al. 2014, Brønnum-Hansen 2017, Seaman et al. 2016) and the United States (Sasson 2016). More recently, much attention has been paid to poor trends in midlife mortality among white Americans, particularly females (Case and Deaton 2015, Montez and Zajacova 2013). As noted by Gillespie et al. (2014), the challenge of reducing young-adult mortality could anticipate a new pattern characterized by increases in lifespan inequality. Our results are further proof of the independence of the two measures during long periods with atypical mortality schedules 
and illustrate the need to monitor lifespan variation for a complete picture of population health.

\section{Age-specific contributions to changes in $e^{\dagger}$}

Lifespan variation increases or decreases depending on the balance of saving lives at "younger ages", which compresses mortality into a smaller age interval and at "older ages" where saving lives leads to greater variability (Zhang and Vaupel 2009, Gillespie et al. 2014, van Raalte and Caswell 2013). Typically, trends in lifespan variation are thought to be driven by changes in the "younger age" component of lifespan variation, with variation from the "older age" mortality component holding steady. For instance, Vaupel et al. (2011) found that old age life disparity was stable at between 2.5 and 8 years from the period 1840 to 2009 in countries of the Human Mortality Database (2016). Gillespie et al. (2014) showed that fluctuation in lifespan variation in Canada, Japan and the United States was almost entirely driven by younger ages. van Raalte et al. (2014) discovered that at similar life expectancy levels, Finnish occupational classes had similar older age lifespan variation, but varied widely in younger age lifespan variability over the time period 1971-2010. By contrast, in this study, we found highly fluctuating lifespan variation owed to fluctuation in both the younger and older age components. For instance, in Bulgaria during the 1987 to 1994 period, lifespan variation increased because of increased mortality at younger ages and continued mortality reduction at older ages.

Below age 5 almost every country experienced sizable progress in averting deaths, particularly in the 1960 to 1980 period. These ages contributed toward decreases in life disparity below age 5 mainly. These results are consistent with previous research documenting improvements in infant mortality and deterioration in young and middle-aged mortality leading to a substantial deterioration in the health status in the region (Chenet et al. 1996).

At the same time, our results revealed a paradox of sorts. On the one hand, between-country differences in lifespan variation were more stable than between-country differences in life expectancy. On the other hand, changes in lifespan variation were more sensitive to year-to-year mortality fluctuations than life expectancy. Measures of dispersion are more sensitive to mortality change in early midlife than life expectancy (van Raalte and Caswell 2013). Mortality between ages 25 and 50 showed more fluctuation than older adult mortality over the period, seen clearly in Figure 1. This explains why life disparity showed greater year-to-year fluctuation than life expectancy. Meanwhile, mortality differences over older working ages and among the early retired have a larger impact on life expectancy than life disparity. This is because these ages are found on either side of the threshold age, with mortality declines (or increases) often offsetting each other, so that the net impact is no change in lifespan variation. As a result, the combination of mortality fluctuation over younger ages with growing mortality differentials at older adult ages can lead to widening between-country inequalities in life expectancy, alongside stable life disparity differences. 
The impact of alcohol on mortality has been extensively studied in Russia, which experienced the largest mortality swings in the region (Leon et al. 1997, Rehm et al. 2007, Shkolnikov et al. 2013; 2001). Alcoholrelated mortality is also known to have played an important role in mortality trends since the 1980s in other Central and Eastern European countries (Rehm et al. 2007), though its specific impact on lifespan variation has not been thoroughly investigated. To date, only Shkolnikov et al. (2003)'s study on Russia between 1979 and 1989 has analyzed the ages and causes of death contributing to changing lifespan variation in the region. They found that early-adult mortality compression during this period was attributed to a decrease in alcoholrelated mortality as a consequence of Gorbachev's anti-alcohol campaign. We extended this cause-of-death analysis to include more countries (Belarus, Czech Republic, Estonia, Latvia, Lithuania, Poland, Russia and Ukraine), and to specifically examine alcohol's impact on lifespan variation in the 1994-2010 post-Soviet years. While 1994 was the height of the crisis following the dissolution of the Soviet Union, the years that followed were characterised by divergence in mortality coinciding with widely differing economic and political transitions to a market economy, and a more recent period of convergence with sustained mortality decline experienced by all countries in the region.

Fluctuating alcohol-related mortality was an important component of the moving life disparity trends in the wider region, although it occurred to different degrees and manifested itself in different causes over the period and in the different regions. Over young ages, a large role was found for the reduction of external cause mortality including traffic accidents in the Baltic countries throughout the period, and in Russia, Belarus and Ukraine from 2000 onwards, whereas Czech Republic and Poland reduced mortality primarily through reductions in IHD, and non-alcohol related mortality. At older ages, between-country differences in mortality reduction seemed to be driven by the extent of IHD and stroke mortality reduction. Overall, alcohol-related mortality (both increases and reductions) had its strongest influence in Russia, Latvia, Lithuania and Estonia, particularly over young-adult ages; while in the rest of the countries, Ukraine, Poland, Belarus and Czech Republic the effect of alcohol-related mortality on changes in lifespan variation was less clear. From this study, we cannot distinguish whether the impact of alcohol on mortality in the former group was stronger because initial consumption levels were higher, leaving more room for improvement, or whether it was because different alcohol consumption patterns emerged between countries in the 1990s and 2000s. Some evidence has shown that alcohol consumption patterns diverged in Russia and Belarus in the 1990s and early 2000s (Grigoriev and Andreev 2015).

Preventing external mortality at young ages has been previously highlighted as an immediate factor to reduce differences in lifespan variability. Firebaugh et al. (2014) argued that allocating resources to reducing 
homicides in the American black population was more likely to narrow racial disparities in lifespan variation than tackling more common causes of death. In this sense, most reductions in life disparity in the region were caused by improvements in mortality at young ages after 1994, particularly in external causes and birth conditions. The decline in these causes of death also helped rising life expectancy and convergence between countries in the region in lifespan variation. This pattern differs from developed countries such as Canada, France, Germany, Japan, among others, where cancers and cardiovascular diseases helped the most to increase life expectancy since 1950, but they did not account for most life disparity reductions (Seligman et al. 2016).

Mortality associated to the most hazardous forms of alcohol consumption, such as alcohol liver disease or poisoning by exposure to alcohol, did not play a central role in the lifespan variation fluctuation. In part, this might be because these are small causes of death to begin with in comparison to much larger causes of death such as IHD or external cause mortality. Nevertheless, some countries, namely Lithuania, Russia and Latvia did show large mortality improvements in these conditions which caused compression of mortality at young ages. These differences have been pointed out previously as a partial explanation to different mortality trends in Lithuania and Belarus (Grigoriev et al. 2015).

Analyzing lifespan variation together with life expectancy contributes to a deeper understanding of the impact of changing mortality trends on population health. Our results show not only that Eastern European countries experience higher lifespan variation and greater fluctuation in the predictability of life compared to other populations, but that life expectancy and life disparity were able to move independently, particularly in periods of stagnation in life expectancy. These uncommon findings, opposing those observed in most developed countries, show that expansion (compression) levels do not necessarily mean lower (higher) life expectancy or mortality deterioration (improvements) when the yearly changes over time are taken into account.

\section{Acknowledgements}

The authors thank the EDSD-2015-16 cohort, Pavel Grigoriev and Domantas Jasilionis for helpful comments to an earlier version of the manuscript.

\section{Funding}

JMA is supported by the Max Planck Society and the University of Southern Denmark. AvR is supported by the European Research Council Grant No. 716323, and received funding from the AXA foundation-funded project Divergence and Causes of Death (MODICOD), and the joint Agence Nationale de la Recherche 
(ANR), Deutsche Forschungsgemeinschaft (DFG) project Disparities in Mortality Trends to Future Health Challenges (DIMOCHA). 


\section{References}

Avenoso, A. and Beckmann, J. (2005). The safety of vulnerable road users in the southern, eastern and central european countries (the sec belt). Brussels: European Transport Safety Council.

Bell, S., Daskalopoulou, M., Rapsomaniki, E., George, J., Britton, A., Bobak, M., Casas, J. P., Dale, C. E., Denaxas, S., Shah, A. D., et al. (2017). Association between clinically recorded alcohol consumption and initial presentation of 12 cardiovascular diseases: population based cohort study using linked health records. BMJ, 356:j909.

Bellis, M., Hughes, K., Cook, P., and Morleo, M. (2009). Off measure: how we underestimate the amount we drink. Alcohol Concern, London.

Brønnum-Hansen, H. (2017). Socially disparate trends in lifespan variation: a trend study on income and mortality based on nationwide Danish register data. BMJ Open, 7(5):83-96.

Bye, E. K. (2008). Alcohol and homicide in Eastern Europe: A time series analysis of six countries. Homicide studies, 12(1):7-27.

Camarda, C. G. (2012). MortalitySmooth: An R package for smoothing Poisson counts with P-splines. Journal of Statistical Software, 50(1):1-24.

Case, A. and Deaton, A. (2015). Rising morbidity and mortality in midlife among white non-Hispanic Americans in the 21st century. Proceedings of the National Academy of Sciences, 112(49):15078-15083.

Caselli, G., Meslé, F., and Vallin, J. (2002). Epidemiologic transition theory exceptions. Genus, pages 9-51.

Chenet, L., McKee, M., Fulop, N., Bojan, F., Brand, H., Hort, A., and Kalbarczyk, P. (1996). Changing life expectancy in central Europe: is there a Single reason? Journal of Public Health, 18(3):329-336.

Colchero, F., Rau, R., Jones, O. R., Barthold, J. A., Conde, D. A., Lenart, A., Nemeth, L., Scheuerlein, A., Schoeley, J., Torres, C., et al. (2016). The emergence of longevous populations. Proceedings of the National Academy of Sciences, 113(48):E7681-E7690.

Edwards, R. D. and Tuljapurkar, S. (2005). Inequality in life spans and a new perspective on mortality convergence across industrialized countries. Population and Development Review, 31(4):645-674.

Evgeny, R. Y. (2010). Beverage-specific alcohol sales and violent mortality in Russia. Adicciones, 22(4).

Ezzati, M. and Lopez, A. D. (2003). Estimates of global mortality attributable to smoking in 2000. The Lancet, 362(9387):847-852.

Firebaugh, G., Acciai, F., Noah, A. J., Prather, C., and Nau, C. (2014). Why lifespans are more variable among blacks than among whites in the United States. Demography, 51(6):2025-2045.

Gillespie, D. O., Trotter, M. V., and Tuljapurkar, S. D. (2014). Divergence in age patterns of mortality change drives international divergence in lifespan inequality. Demography, 51(3):1003-1017.

Grigoriev, P. and Andreev, E. M. (2015). The huge reduction in adult male mortality in Belarus and Russia: is it attributable to anti-alcohol measures? PLoS one, 10(9):e0138021.

Grigoriev, P., Jasilionis, D., Shkolnikov, V. M., Meslé, F., and Vallin, J. (2015). Spatial variation of male alcohol-related mortality in Belarus and Lithuania. The European Journal of Public Health, page ckv060.

Grigoriev, P., Meslé, F., Shkolnikov, V. M., Andreev, E., Fihel, A., Pechholdova, M., and Vallin, J. (2014). The recent mortality decline in Russia: Beginning of the cardiovascular revolution? Population and Development review, 40(1):107-129.

Horiuchi, S., Wilmoth, J. R., and Pletcher, S. D. (2008). A decomposition method based on a model of continuous change. Demography, 45(4):785-801. 
Human Cause-of-Death Database (2016). French Institute for Demographic Studies (France) and Max Planck Institute for Demographic Research (Germany).

Human Mortality Database (2016). University of California, Berkeley (USA), and Max Planck Institute for Demographic Research (Germany).

Kauhanen, J., Kaplan, G. A., Goldberg, D. E., and Salonen, J. T. (1997). Beer binging and mortality: results from the Kuopio ischaemic heart disease risk factor study, a prospective population based study. $B m j, 315(7112): 846-851$.

Klatsky, A., Friedman, G., and Siegelaub, A. (1974). Alcohol consumption before myocardial infarction. Results from the Kaiser-Permanente epidemiologic study of myocardial infarction. Annals of internal medicine, 81(3):294.

Kraus, L., Østhus, S., Amundsen, E. J., Piontek, D., Härkönen, J., Legleye, S., Bloomfield, K., Mäkelä, P., Landberg, J., and Törrönen, J. (2015). Changes in mortality due to major alcohol-related diseases in four Nordic countries, France and Germany between 1980 and 2009: a comparative age-period-cohort analysis. Addiction, 110(9):1443-1452.

Leon, D. A. (2011). Trends in European life expectancy: a salutary view. International journal of epidemiology, 40(2):271-277.

Leon, D. A., Chenet, L., Shkolnikov, V. M., Zakharov, S., Shapiro, J., Rakhmanova, G., Vassin, S., and McKee, M. (1997). Huge variation in Russian mortality rates 1984-94: artefact, alcohol, or what? The lancet, 350(9075):383-388.

Leon, D. A. and Shkolnikov, V. M. (1998). Social stress and the russian mortality crisis. JAMA, 279(10):790791.

Livingston, M. and Callinan, S. (2015). Underreporting in alcohol surveys: whose drinking is underestimated? Journal of studies on alcohol and drugs, 76(1):158-164.

Mackenbach, J. P., Stirbu, I., Roskam, A.-J. R., Schaap, M. M., Menvielle, G., Leinsalu, M., and Kunst, A. E. (2008). Socioeconomic inequalities in health in 22 European countries. New England Journal of Medicine, 358(23):2468-2481.

Mäkelä, P. and Österberg, E. (2009). Weakening of one more alcohol control pillar: a review of the effects of the alcohol tax cuts in Finland in 2004. Addiction, 104(4):554-563.

Martikainen, P., Mäkelä, P., Peltonen, R., and Myrskylä, M. (2014). Income differences in life expectancy: the changing contribution of harmful consumption of alcohol and smoking. Epidemiology, 25(2):182-190.

McKee, M. and Shkolnikov, V. (2001). Understanding the toll of premature death among men in Eastern Europe. BMJ: British Medical Journal, 323(7320):1051.

McKee, M., Süzcs, S., Sárváry, A., Ádany, R., Kiryanov, N., Saburova, L., Tomkins, S., Andreev, E., and Leon, D. A. (2005). The composition of surrogate alcohols consumed in Russia. Alcoholism: Clinical and Experimental Research, 29(10):1884-1888.

Menon, K. N., Gores, G. J., and Shah, V. H. (2001). Pathogenesis, diagnosis, and treatment of alcoholic liver disease. In Mayo Clinic Proceedings, volume 76, pages 1021-1029. Elsevier.

Meslé, F. (2004). Mortality in Central and Eastern Europe: long-term trends and recent upturns. Demographic Research, 2:45-70.

Meslé, F., Vallin, J., and Shkolnikov, V. (2000). Reversal of mortality decline: the case of contemporary Russia. World Health Statistics Quarterly, 51(2-4):191-206.

Montez, J. K. and Zajacova, A. (2013). Trends in mortality risk by education level and cause of death among US White women from 1986 to 2006. American journal of public health, 103(3):473-479. 
Moser, K., Shkolnikov, V., and Leon, D. A. (2005). World mortality 1950-2000: divergence replaces convergence from the late 1980s. Bulletin of the World Health Organization, 83(3):202-209.

Popova, S., Rehm, J., Patra, J., and Zatonski, W. (2007). Comparing alcohol consumption in central and eastern Europe to other European countries. Alcohol and alcoholism, 42(5):465-473.

R Core Team (2000). R language definition.

Rabinovich, L., Brutscher, P.-B., de Vries, H., Tiessen, J., Clift, J., and Reding, A. (2009). The affordability of alcoholic beverages in the European Union: understanding the link between alcohol affordability, consumption and harms. RAND Corporation Santa Monica, CA.

Rau, R., Bohk, C., Muszyńska, M. M., and Vaupel, J. (2013). Rates of mortality improvement on the lexis surface. Technical report, Max Planck Institute for Demographic Research.

Rehm, J., Baliunas, D., Borges, G. L., Graham, K., Irving, H., Kehoe, T., Parry, C. D., Patra, J., Popova, S., Poznyak, V., et al. (2010). The relation between different dimensions of alcohol consumption and burden of disease: an overview. Addiction, 105(5):817-843.

Rehm, J., Room, R., Graham, K., Monteiro, M., Gmel, G., and Sempos, C. T. (2003). The relationship of average volume of alcohol consumption and patterns of drinking to burden of disease: an overview. Addiction, 98(9):1209-1228.

Rehm, J., Sulkowska, U., Mańczuk, M., Boffetta, P., Powles, J., Popova, S., and Zatoński, W. (2007). Alcohol accounts for a high proportion of premature mortality in central and eastern Europe. International journal of epidemiology, 36(2):458-467.

Robine, J.-M. (2001). Redefining the stages of the epidemiological transition by a study of the dispersion of life spans: The case of France. Population: An English Selection, pages 173-193.

Roerecke, M. and Rehm, J. (2014). Alcohol consumption, drinking patterns, and ischemic heart disease: a narrative review of meta-analyses and a systematic review and meta-analysis of the impact of heavy drinking occasions on risk for moderate drinkers. BMC medicine, 12(1):182.

Rychtarikova, J. (2004). The case of the czech republic: Determinants of the recent favourable turnover in mortality. Demographic Research, 2:105-138.

Sasson, I. (2016). Trends in life expectancy and lifespan variation by educational attainment: United States, 1990-2010. Demography, 53(2):269-293.

Seaman, R., Leyland, A. H., and Popham, F. (2016). Increasing inequality in age of death at shared levels of life expectancy: a comparative study of scotland and England and Wales. SSM-population health, $2: 724-731$.

Seligman, B., Greenberg, G., and Tuljapurkar, S. (2016). Equity and length of lifespan are not the same. Proceedings of the National Academy of Sciences, 113(30):8420-8423.

Shkolnikov, V., Andreev, E., McKee, M., and Leon, D. (2013). Components and possible determinants of the decrease in Russian mortality in 2004-2010. Demographic research, 28(32):917-950.

Shkolnikov, V., McKee, M., and Leon, D. A. (2001). Changes in life expectancy in Russia in the mid-1990s. The Lancet, 357(9260):917-921.

Shkolnikov, V. M., Andreev, E. E., and Begun, A. Z. (2003). Gini coefficient as a life table function: computation from discrete data, decomposition of differences and empirical examples. Demographic Research, $8(11): 305-358$.

Shkolnikov, V. M., Andreev, E. M., Jasilionis, D., Leinsalu, M., Antonova, O. I., and McKee, M. (2006). The changing relation between education and life expectancy in central and eastern europe in the 1990s. Journal of Epidemiology \&3 Community Health, 60(10):875-881. 
Shkolnikov, V. M., Andreev, E. M., Zhang, Z., Oeppen, J., and Vaupel, J. W. (2011). Losses of expected lifetime in the United States and other developed countries: methods and empirical analyses. Demography, $48(1): 211-239$.

Smits, J. and Monden, C. (2009). Length of life inequality around the globe. Social Science $\mathscr{E}$ Medicine, 68(6):1114-1123.

Timonin, S., Shkolnikov, V. M., Jasilionis, D., Grigoriev, P., Jdanov, D. A., and Leon, D. A. (2016). Disparities in length of life across developed countries: measuring and decomposing changes over time within and between country groups. Population health metrics, 14(1):29.

van Raalte, A. A. and Caswell, H. (2013). Perturbation analysis of indices of lifespan variability. Demography, 50(5):1615-1640.

van Raalte, A. A., Martikainen, P., and Myrskylä, M. (2014). Lifespan variation by occupational class: compression or stagnation over time? Demography, 51(1):73-95.

Vaupel, J. W. and Canudas-Romo, V. (2003). Decomposing change in life expectancy: A bouquet of formulas in honor of Nathan Keyfitzs 90th birthday. Demography, 40(2):201-216.

Vaupel, J. W., Zhang, Z., and van Raalte, A. A. (2011). Life expectancy and disparity: an international comparison of life table data. BMJ open, 1(1):e000128.

Wilmoth, J. R. and Horiuchi, S. (1999). Rectangularization revisited: Variability of age at death within human populations. Demography, 36(4):475-495.

World Health Organization (2000). The world health report 2000: health systems: improving performance.

World Health Organization (2009). European status report on road safety: towards safer roads and healthier transport choices.

World Health Organization (2013). Global status report on road safety 2013: supporting a decade of action.

Zhang, Z. and Vaupel, J. W. (2009). The age separating early deaths from late deaths. Demographic Research, 20(29):721-730. 


\section{Figures and tables}

Table 1: Classification of causes-of death amenable to alcohol consumption

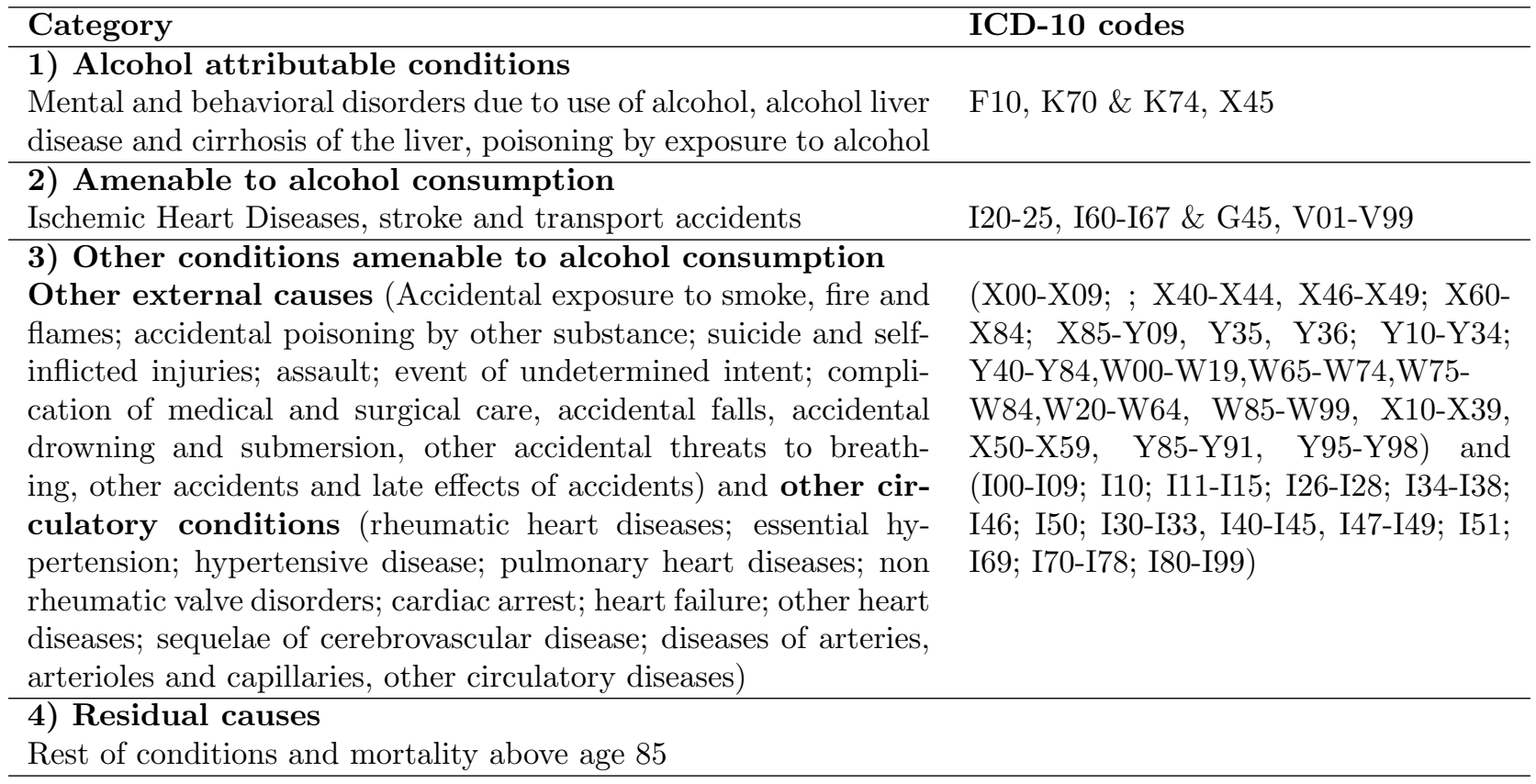


Table 2: Cause-specific contributions to the change in $e^{\dagger}$ for males, 1994-2000 \& 2000-2010

\begin{tabular}{|c|c|c|c|c|c|c|c|c|c|c|c|c|}
\hline Period & Country & $\begin{array}{l}\text { Attributable } \\
\text { to alcohol }\end{array}$ & $\begin{array}{l}\text { Transport } \\
\text { accidents }\end{array}$ & Stroke & IHD & $\begin{array}{r}\text { Other } \\
\text { external }\end{array}$ & $\begin{array}{r}\text { Other } \\
\text { circulatory }\end{array}$ & $\begin{array}{r}\text { Birth } \\
\text { conditions }\end{array}$ & Cancers & $\begin{array}{r}\text { Infectious } \\
\& \text { respiratory }\end{array}$ & Rest & Total \\
\hline \multirow[t]{8}{*}{ 1994-2000 } & Belarus & 0.03 & -0.03 & -0.04 & -0.07 & 0.01 & -0.01 & -0.08 & -0.10 & 0.01 & 0.10 & -0.28 \\
\hline & Czech Republic & 0.01 & -0.06 & 0.01 & -0.01 & -0.09 & -0.04 & -0.19 & -0.16 & 0.01 & 0.12 & -0.52 \\
\hline & Estonia & -0.04 & -0.41 & 0.15 & 0.19 & -0.78 & -0.04 & -0.22 & -0.14 & -0.01 & 0.18 & -1.30 \\
\hline & Latvia & -0.11 & -0.14 & 0.14 & 0.18 & -0.64 & -0.17 & -0.14 & -0.09 & -0.12 & 0.13 & -1.09 \\
\hline & Lithuania & -0.28 & -0.04 & 0.05 & 0.15 & -0.39 & 0.01 & -0.26 & -0.15 & -0.09 & 0.17 & -1.00 \\
\hline & Poland & 0.01 & -0.08 & 0.02 & -0.04 & -0.18 & 0.17 & -0.34 & -0.13 & -0.07 & 0.24 & -0.64 \\
\hline & Russia & -0.07 & -0.03 & 0.00 & -0.00 & -0.02 & 0.10 & -0.12 & 0.00 & 0.09 & 0.04 & -0.05 \\
\hline & Ukraine & 0.04 & -0.07 & 0.04 & -0.07 & -0.04 & 0.00 & -0.03 & -0.02 & 0.21 & -0.02 & 0.06 \\
\hline \multirow[t]{8}{*}{$2000-2010$} & Belarus & 0.02 & -0.10 & -0.05 & -0.13 & -0.33 & 0.11 & -0.25 & -0.02 & 0.01 & 0.08 & -0.74 \\
\hline & Czech Republic & -0.01 & -0.14 & 0.09 & -0.11 & -0.11 & 0.02 & -0.07 & -0.23 & 0.00 & 0.11 & -0.56 \\
\hline & Estonia & -0.17 & -0.23 & 0.18 & 0.20 & -0.60 & -0.35 & -0.26 & -0.15 & -0.14 & -0.15 & -1.52 \\
\hline & Latvia & -0.01 & -0.34 & 0.18 & 0.06 & -0.47 & -0.07 & -0.33 & -0.02 & -0.04 & 0.76 & -1.04 \\
\hline & Lithuania & 0.05 & -0.21 & 0.02 & -0.00 & -0.35 & 0.11 & -0.10 & -0.03 & 0.01 & -0.44 & -0.50 \\
\hline & Poland & -0.01 & -0.16 & 0.04 & -0.07 & -0.06 & 0.14 & -0.16 & -0.16 & 0.01 & 0.11 & -0.43 \\
\hline & Russia & -0.06 & -0.10 & 0.25 & -0.00 & -0.70 & 0.03 & -0.32 & 0.01 & -0.03 & 0.20 & -0.92 \\
\hline & Ukraine & -0.08 & -0.04 & 0.02 & -0.07 & -0.53 & -0.03 & -0.15 & -0.01 & 0.05 & 0.05 & -0.84 \\
\hline
\end{tabular}


Figure 1: Male mortality surface showing rates of mortality improvements

\section{Rates of mortality improvements}

Males
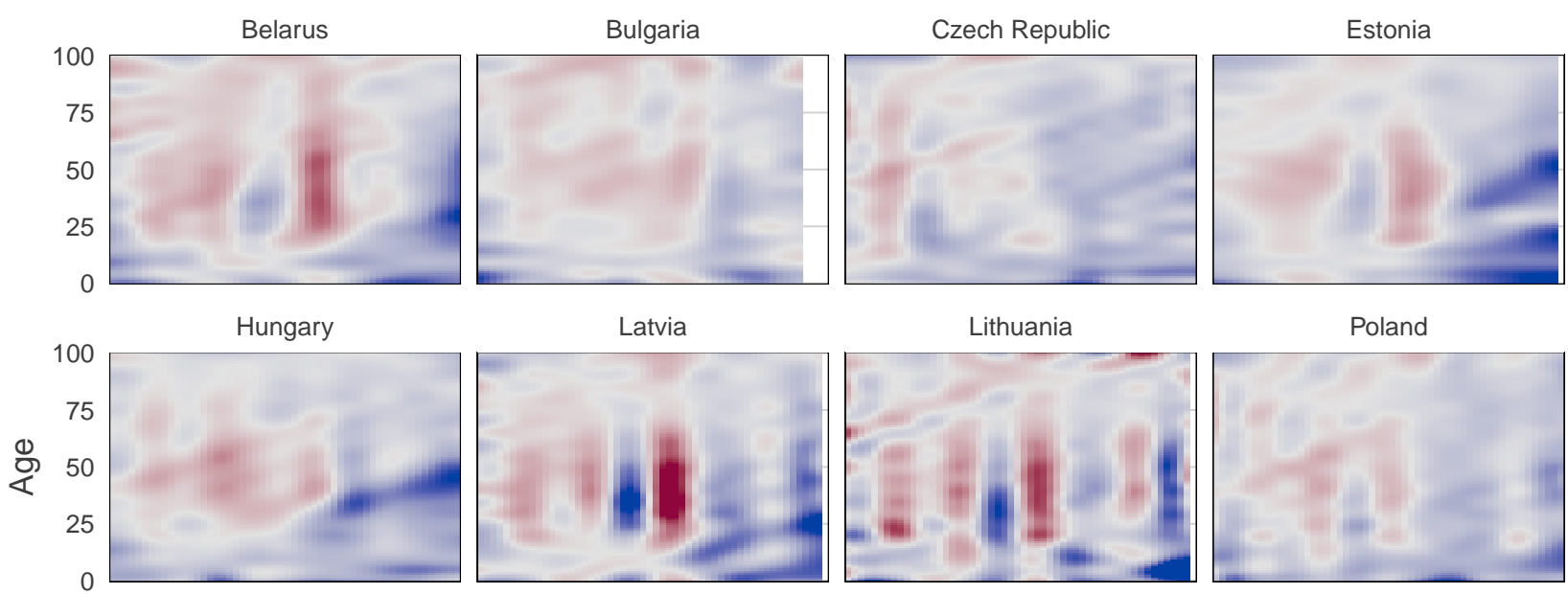

Poland
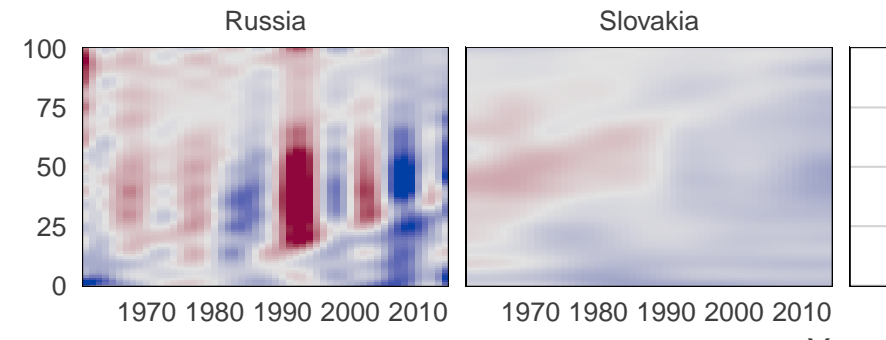

Slovenia
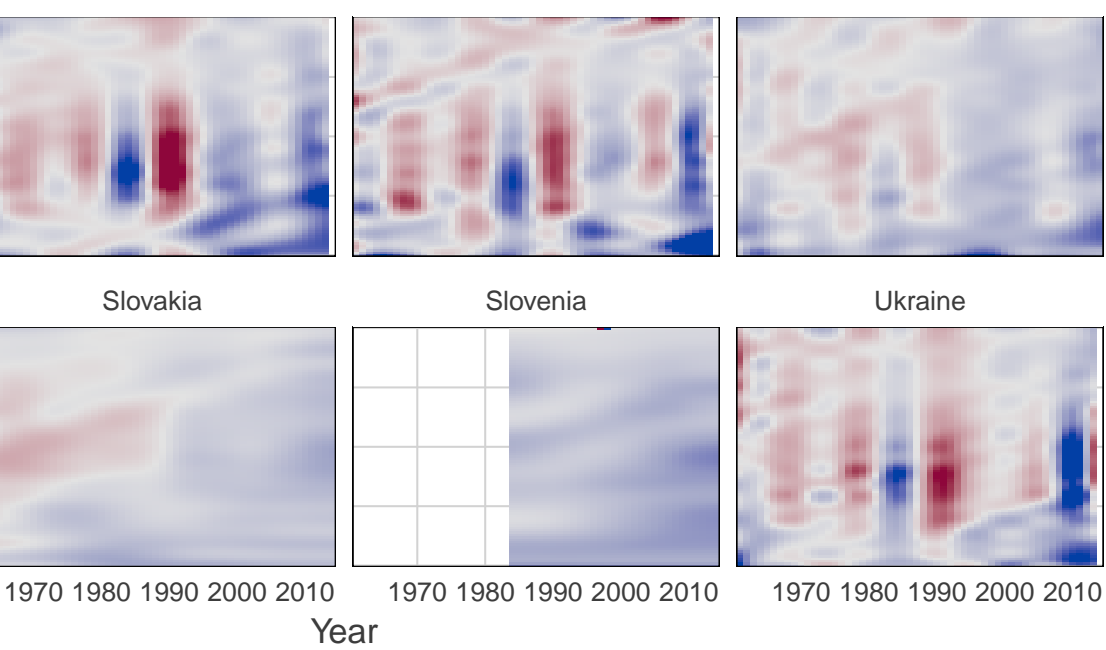

19701980199020002010

19701980199020002010

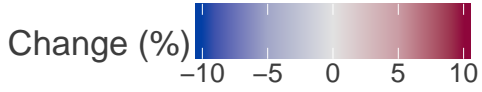

Source: own calculations based on Human Mortality Database (2016) data. Note: The regular light -grey areas indicate no data available. 
Figure 2: Trends in males life expectancy $\left(e_{0}\right)$ and lifespan disparity $\left(e^{\dagger}\right)$ for 12 Eastern European countries, $1960-2014$

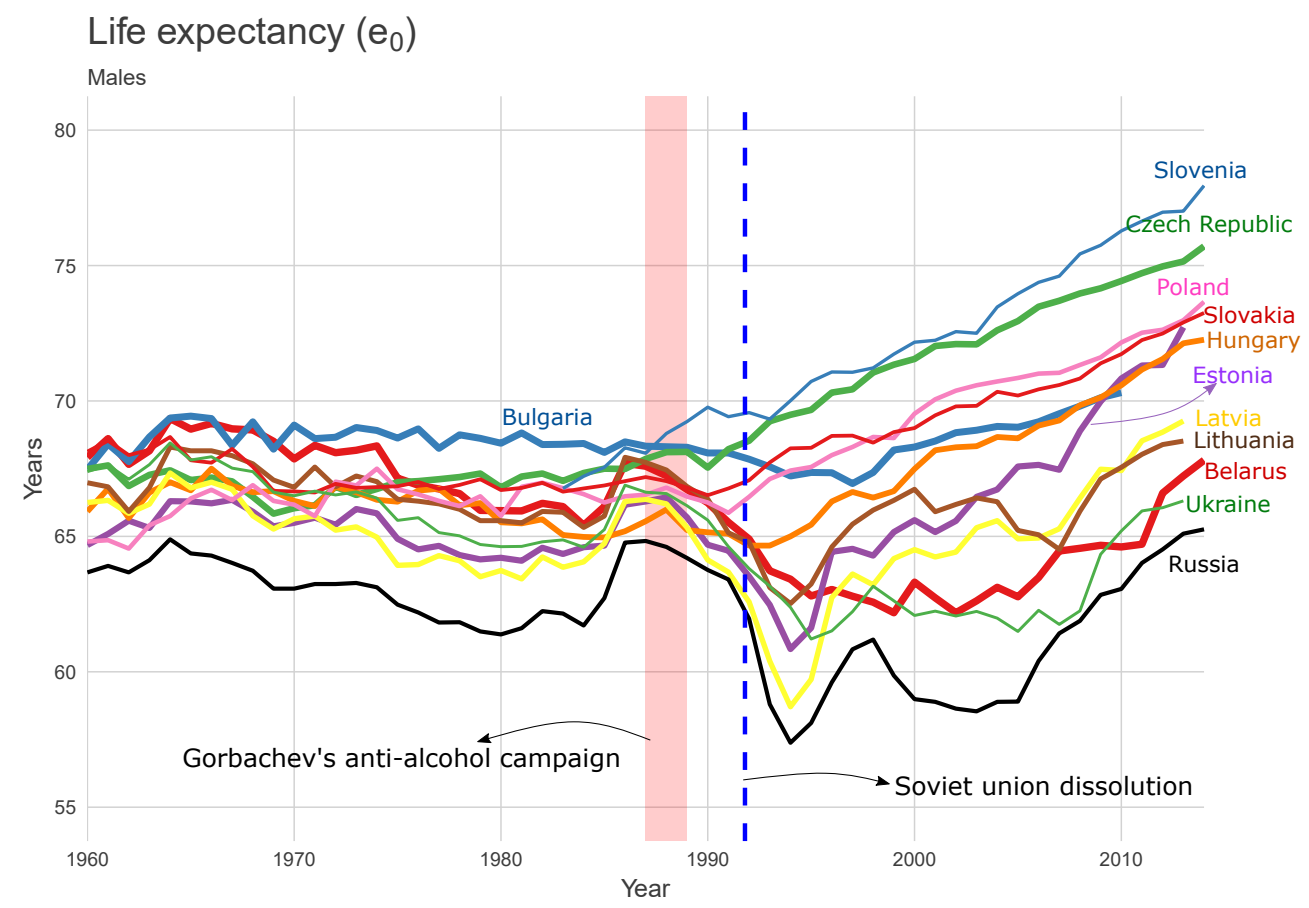

Life disparity $\left(\mathrm{e}^{\dagger}\right)$

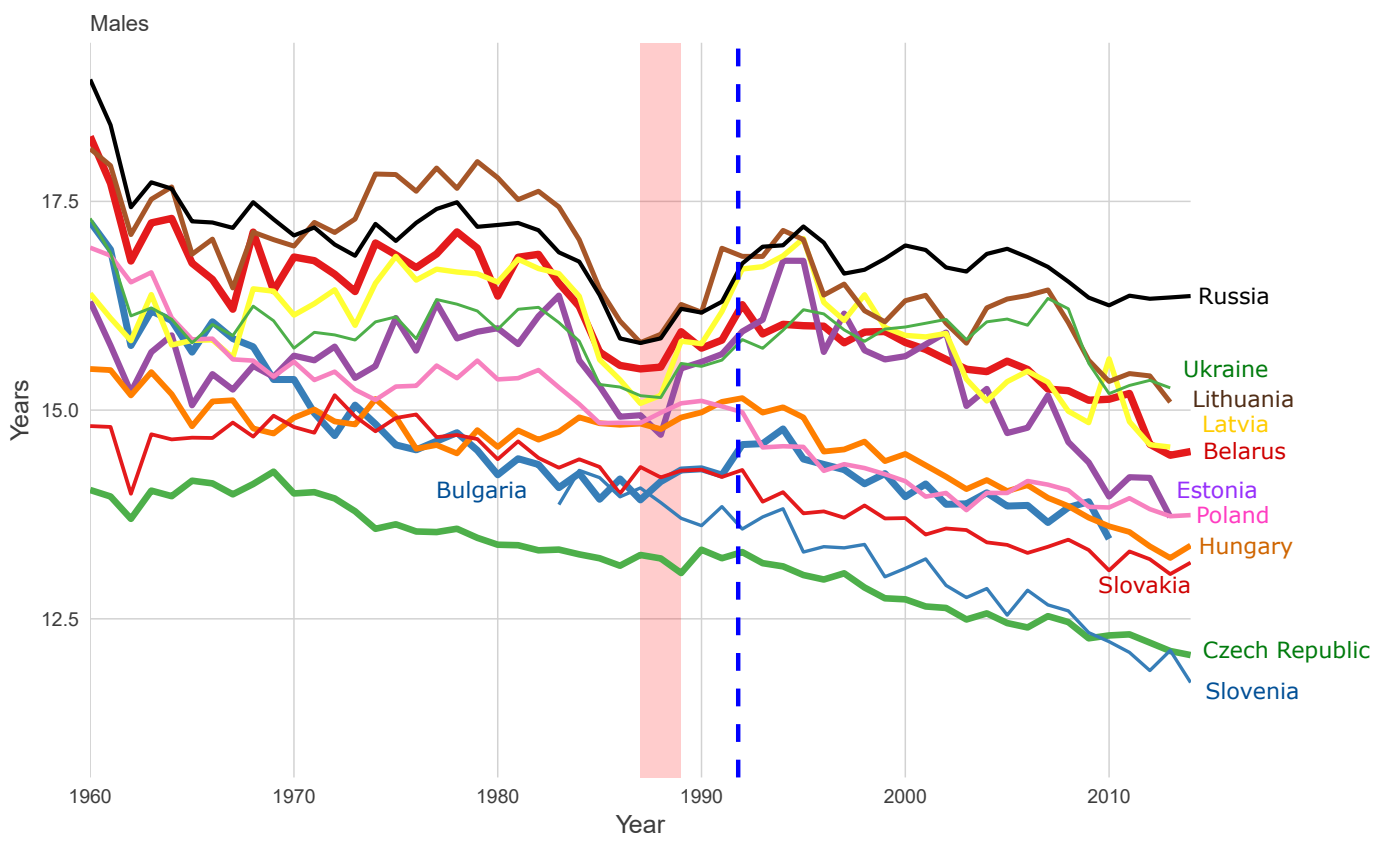

Source: own calculations based on Human Mortality Database (2016) data. 
Figure 3: Absolute and relative yearly changes in life expectancy and lifespan disparity, 1960-2010

\section{Association between changes in $\mathrm{e}_{0}$ and $\mathrm{e}^{\dagger}$, males.}

Absolute changes (years)

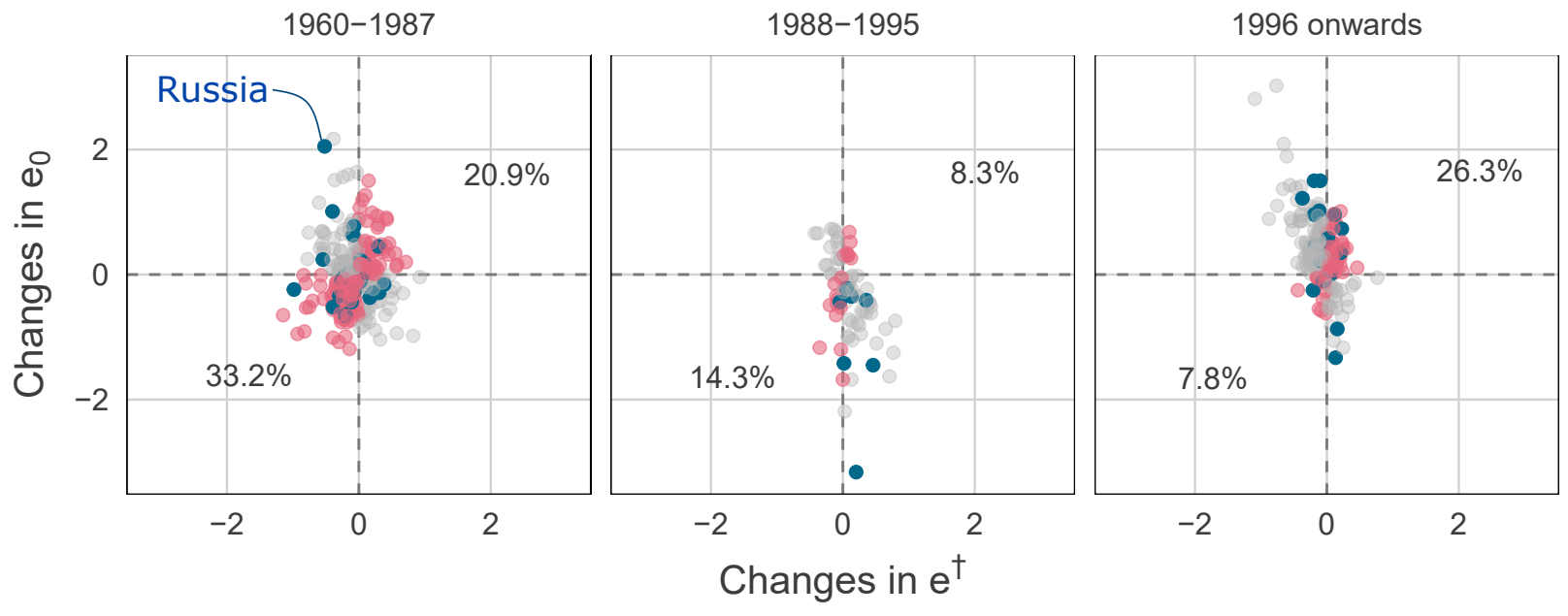

Relative changes (\%)
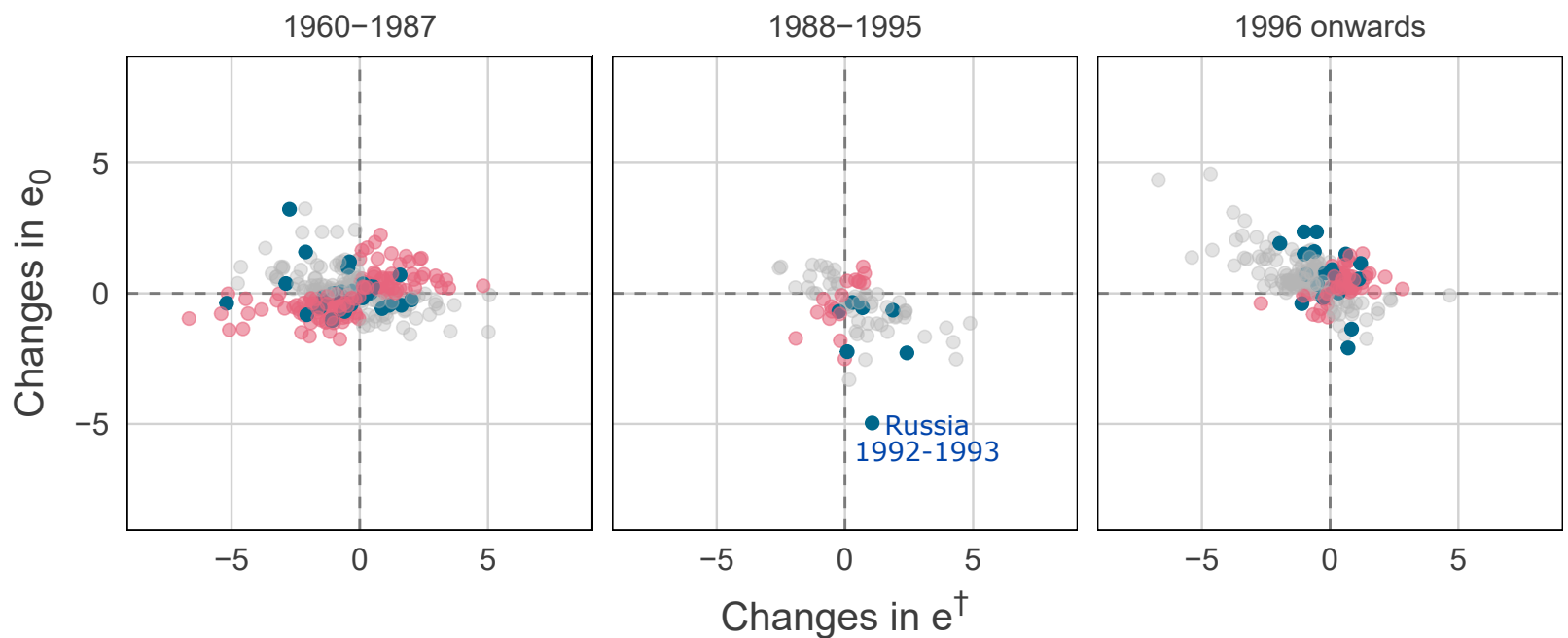

Source: own calculations based on Human Mortality Database (2016) data. Note: data for Slovenia begins in 1983. The black dots are related to changes experienced in Russia. The percentages correspond to the total changes occurred during each period. 
Figure 4: Males' age-specific contributions to the change in lifespan disparity $e^{\dagger}$ by periods.

\section{Age-contribution to changes in life disparity by period}

Males, negative values decrease $\mathrm{e}^{\dagger}$ and positive values increase $\mathrm{e}^{\dagger}$
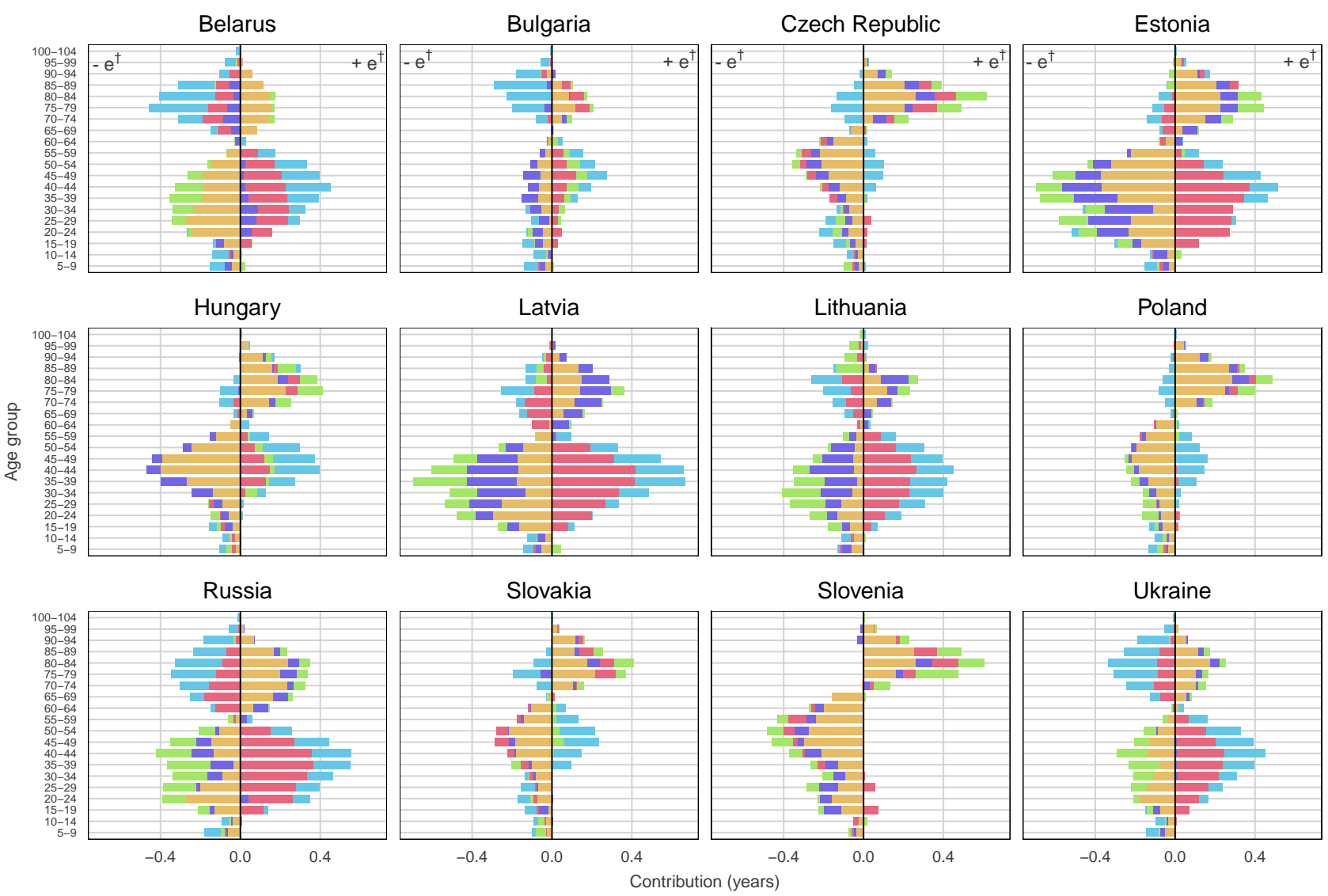

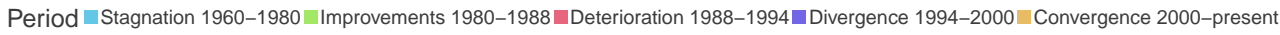

Source: own calculations based on Human Mortality Database (2016) data. Note: data for Slovenia begins in 1983. 
Figure 5: Cause specific contributions to the change in male lifespan disparity $e^{\dagger}, 1994-2000$

\section{Age-contribution to changes in life disparity by cause of death}

Males, 1994-2000
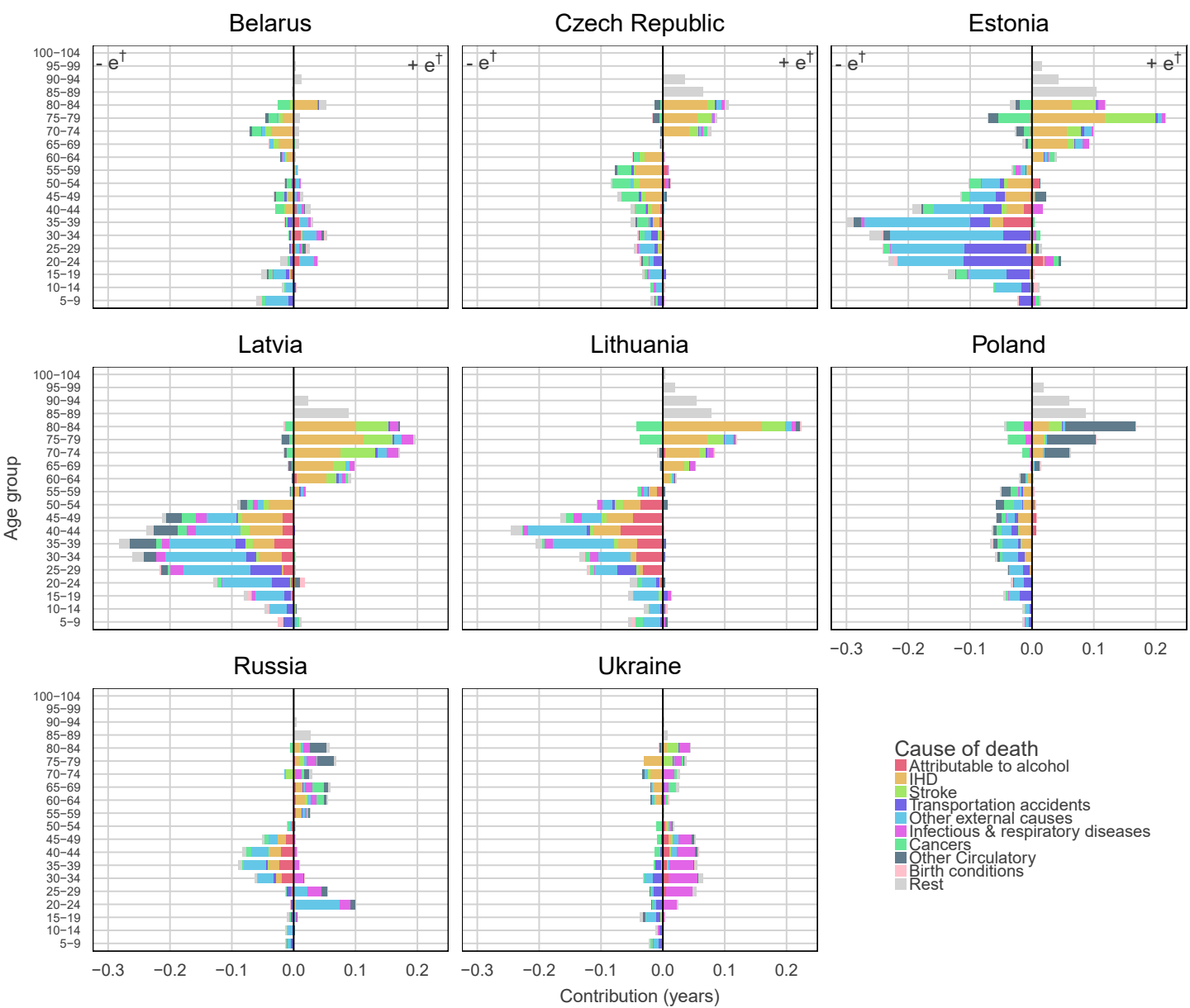

Source: own calculations based on Human Cause-of-Death Database (2016) data. 
Figure 6: Cause specific contributions to the change in male lifespan disparity $e^{\dagger}, 2000-2010$

Age-contribution to changes in life disparity by cause of death Males, 2000-2010
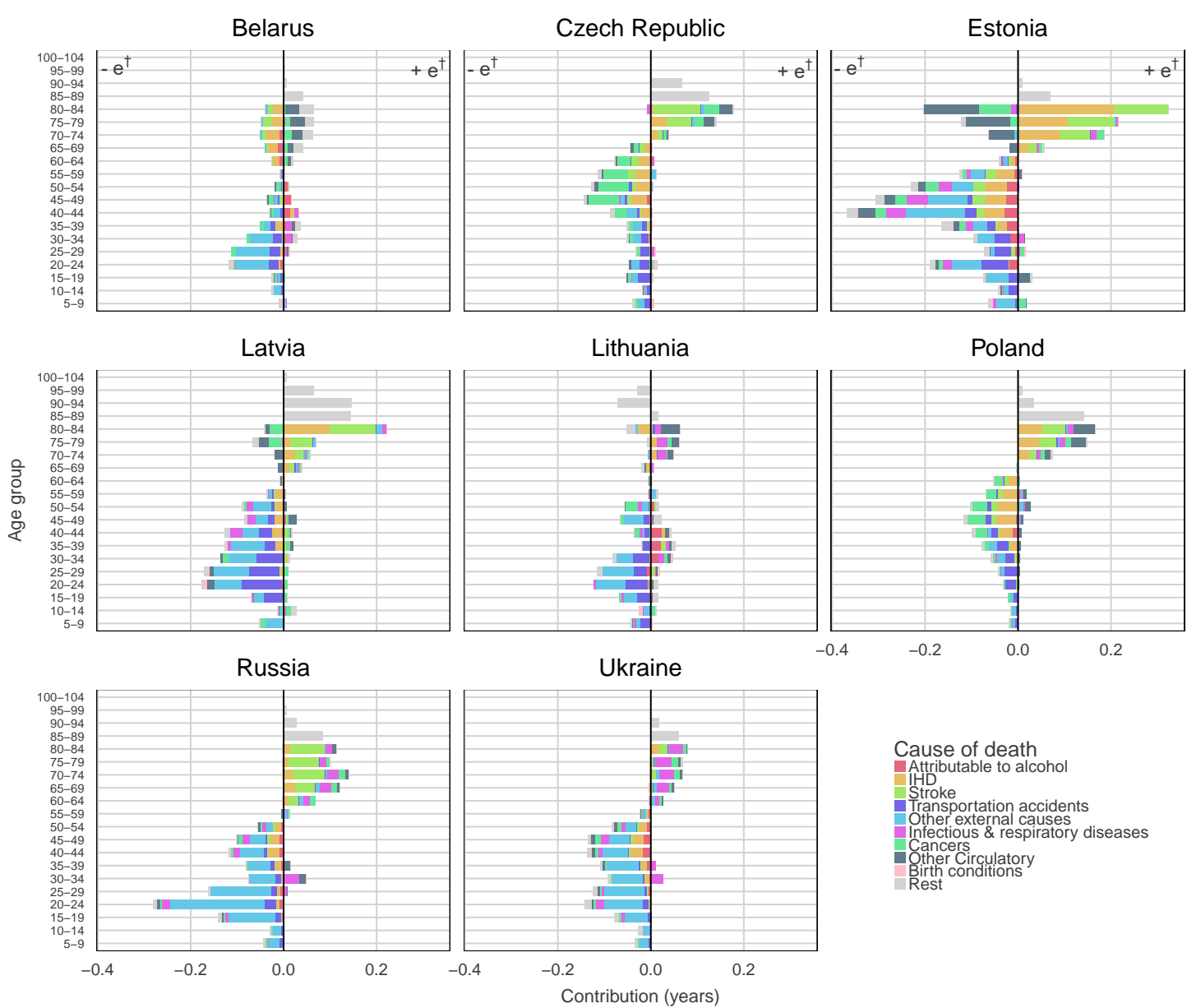

Source: own calculations based on Human Cause-of-Death Database (2016) data. Note: data for Poland ends in 2009. 